\title{
Student Perceptions of the Instruction Sheets in Face-To-Face and Remotely- Operated Engineering Laboratory Learning
}

\begin{abstract}
The laboratory instruction sheet (sometimes called a laboratory manual), together with the equipment used by students, is an essential resource for laboratory work. It has a direct influence over all the interactions that can occur in the laboratory activity, of which studentequipment is the only common synchronous interaction in both face-to-face and remote-access laboratories. This article offers a student perspective on the function, utility, and importance of laboratory instruction sheets in Engineering along with their preferred design for both face-toface and remote modes. Both qualitative and quantitative investigations were made for studying students' perceptions. The laboratory sheet was found to be a contributing factor to student satisfaction for student-equipment interactions in face-to-face laboratories and important to students' experience in remote-access laboratories in giving them a feel of operating real equipment. Student responses indicated that the instruction sheet should meet different content requirements and emphases that depend upon the laboratory mode and different levels of student academic achievement.
\end{abstract}

\section{Introduction}

Today, in an era of educational transformation with the impact of technology upon the education sector, engineering students have the opportunity to carry out laboratory work in two different modes: conventional face-to-face work that requires their co-location within the physical laboratory, or technology-mediated using the internet (often termed a "remote laboratory") (Lang, 2012; Tolba \& Elawady, 2016; Vuthaluru et al., 2013). There is a third category of laboratory mode called the simulated or virtual laboratory where students perform simulated experiments, and not by manipulating real physical equipment. However, the article deals specifically with the laboratory modes that require manipulation of real physical equipment which are face-to-face and remotely-operated laboratories.

The nature of the laboratory mode considerably influences the types of student experience during the conduct of the laboratory work (Corter et al., 2007; Ma \& Nickerson, 2006). In the face-to-face laboratory, students interact with their peers, instructors, and equipment to carry out the assigned activities. By contrast, in the remote laboratory students only interact with the equipment in real time while conducting their experimental investigation (Lowe, Murray, Li, \& Lindsay, 2012). Students are able to interact with other students and instructors but this is asynchronous and different to that in the face-to-face laboratory because it is generally mediated by internet-supported platforms (Machotka \& Nedic, 2006; Teng, Considine, Nedic, \& Nafalski, 2016; Zubía \& Alves, 2011). However, the Netlab, a remotely-operated laboratory developed by University of South Australia, allowed for up to three students to synchronise their laboratory work and provided all students with full control over the equipment (Machotka \& Nedic, 2006; Nafalski et al., 2009).

The interactions that occur during laboratory learning activities have been observed and valued both in on-campus and distance-mode education (Anderson, 2003). There are broadly two types of interactions in any laboratory setting: social and individual interactions (Bright, Lindsay, Lowe, Murray, \& Liu, 2008). Social interactions comprise interactions between students and also those between students and their instructors, while individual interactions feature students working with the equipment (Webb \& Webb, 2005) during the laboratory work. Each interaction type makes a unique contribution towards students attaining the learning 
outcomes of the laboratory activity (Ogot, Elliott, \& Glumac, 2003). It is generally the blend of the above interaction types that make the laboratory experience valuable for students' learning and their satisfaction. Nikolic et al. (2015) have reported on student's satisfaction for the laboratory work, which was significantly influenced by laboratory instruction sheets that described the laboratory procedures and all related aspects in 'good length'.

The interactions that occur in an Engineering laboratory are influenced and often guided by the laboratory instruction sheet (sometimes referred to as the laboratory manual) which is an integral component of the laboratory specification and its conduct (Gregory \& Di Trapani, 2012; Mahmood Khan \& Alghazzawi, 2011). This holds true for both face-to-face and remote laboratory work. The laboratory instruction sheet is the basis for the demonstration of the laboratory work for the instructors, whereas, it is a guide for students to carry out the laboratory experiment (Watai, Brodersen, \& Brophy, 2005). Whenever a new laboratory is created conceptually and then practically realised, both of these processes incorporate the design of the laboratory instruction sheet (Coppens, 2016; Selvaduray, 1995).

Craven (2003) studied the influence of traditional and project-based laboratory instruction sheets on student's performance, while Patterson (2011) reported on the effects of multimedia laboratory instructions on student's learning. The impact of design of instruction sheets has been reported in the work of Reid and Shah (2007). The depth of information and clarity of instructions in the laboratory instruction sheet can effectively provide ideas about the nature of the laboratory work and also its expected learning outcomes (Coppens, 2016). However, the importance of the laboratory instruction sheet in relation to the interactions that occur in the laboratory has not received sufficient attention in the research literature. Students in both faceto-face and remote laboratory modes rely heavily on the laboratory instruction sheet, not only for procedural aspects of the activity undertaken but also for the development of conceptual understanding as well as the synthesis and interpretation of results; these elements can also be enabled by the interactions that occur in laboratory work. The present article serves to increase understanding of the multifaceted function of the instruction sheet and how this might depend upon whether the laboratory activity is undertaken in face-to-face or remote-access mode.

Related research that has been carried out so far has focused on the effects of interactions on students' learning outcomes (Couteur, 2009; Högström, Ottander, \& Benckert, 2010; Lindsay $\&$ Good, 2005; Sher, 2009). Much less emphasis has been given to the factors that influence the interaction types that occur in engineering laboratories. Students' interactions with equipment are considered the most important and frequent of all interaction types. There are multiple components involved with this interaction depending upon the laboratory mode. In face-to-face laboratories, student-equipment interaction involves the students, the laboratory instruction sheet and the equipment. Remotely operated laboratories provide the option of using the capabilities of the internet in addition to the laboratory instruction sheet and the equipment.

Students are given demonstrations of the experiment to be conducted, apprised of safety matters involved and briefed on the learning objectives to be attained by performing the experiment (Watai et al., 2005). During these processes students and instructors continuously interact with each other (Kirkup, Varadharajan, \& Braun, 2016). The frequency and intensity of the interactions are likely to be influenced by the clarity and comprehensiveness of the laboratory instruction sheet (Braun, Kirkup, \& Chadwick, 2018). Students frequently ask instructors for help in matters that are either not covered in the laboratory instruction sheet or are not readily understood. The interactions between students and instructors make important contributions to students' acquiring of essential engineering laboratory skills (Kirkup et al., 
2016). Thus, the laboratory instruction sheet plays an important role in the various interactions that occur in the laboratory setting.

Finally, some studies have advocated reform of the laboratory instruction sheet but these are mainly focused on content revision (Craven, 2003; Hou, Zhong, \& Ayala, 2017; Mahmood Khan \& Alghazzawi, 2011) or suggest various access mechanisms to laboratory instruction sheets for better achievement of learning outcomes (Maldarelli et al., 2009; Patterson, 2011).

The study reported in this article offers a student perspective on the function, utility, and importance of laboratory instruction sheets in Engineering laboratory work. The study first explores the intricate relationship between the interactions that occur in laboratory work and the laboratory instruction sheet because these can play a major role in both the performance and satisfaction of students in each of face-to-face and remotely accessed laboratory work. Thereafter, consideration is given to how the design of laboratory instruction sheets might depend upon student performance and laboratory mode. The overarching purpose of this article is to provide insights that can lead to the improved design of instruction sheets for effective laboratory learning.

This study, therefore, served to provide answers to the following research questions (RQ):

RQ1 How important (relative to other interactions that occur in the laboratory) is the laboratory instruction sheet perceived to be by students in face-to-face and remoteaccess modes?

RQ2 How important is the laboratory instruction sheet in the facilitation of studentequipment interactions in face-to-face and remote-access laboratory modes?

RQ3 How important is the laboratory instruction sheet as a determinant of students' level of satisfaction with their laboratory work in face-to-face and remote-access laboratory work?

RQ4 Do students identify different requirements of laboratory instruction sheets for face-toface and remote-access modes of conducting laboratories?

RQ5 Are students' expectations of, and dependencies upon, the laboratory instruction sheet related to their performance in laboratory learning?

This article is structured as follows. A conceptual framework of the relationship between the instruction sheet, laboratory interactions, and laboratory activities is first developed. The first investigative component addresses students' perceptions of the importance of the laboratory instruction sheet based on survey instruments (RQ1 and RQ2). The second investigation examines the relationship between student satisfaction and the laboratory instruction sheet via a correlation analysis (RQ3). The third component of the study addresses students' perceived needs of the laboratory instruction sheet using quantitative and qualitative methods (RQ4 and RQ5). Throughout these three components, results from face-to-face and remote-access modes are compared and contrasted. Finally, a discussion of these interrelated components is presented and overall conclusions are then drawn. 


\section{Overview of laboratory instruction sheets in face-to-face and remote engineering laboratories}

The laboratory instruction sheet used in engineering laboratories generally presents the theory (often as a recapitulation of theory already covered in the associated lecture course) that underpins the experiment, describes procedures for carrying out the experiment and usually includes tables to guide data collection and figures that illustrate the laboratory activity (Kirkup et al., 2016; Selvaduray, 1995).

The components listed above generally appear in a logical order in the laboratory instruction sheet. The laboratory sheet opens with the title of the experiment or investigation. It then sequentially introduces the set of equipment that will be used to carry out the experiment. A brief background of the underlying theory that governs the experimental phenomena being studied is then presented. This background is deliberately included to provide students with a link between their practical work and lecture-based learning. Detailed step-by-step instructions for carrying out the actual work then follows. The remainder of the laboratory instruction sheet comprises tables to collect data and discussion questions that promote reflection on the validity and the meaning of their results, the first to assess the correctness of their implementation of procedures and the operation of the equipment, while the second is to check that students have understood the concepts that the practical work is designed to prove or illustrate. Some laboratory sheets also incorporate references for students to follow up on or address any query they may have during the experiment. While the foregoing is a general description, the contents of a laboratory instruction sheet and its use will vary depending upon the mode in which the laboratory work is conducted.

In the face-to-face laboratory, students are physically co-located with the experimental apparatus and carry out the experiment under real-time supervision by the instructor and in collaboration with laboratory partners. Instructors present or overview the contents of the laboratory instruction sheet and remain available to provide help when required and ensure that laboratory-sheet instructions are followed correctly and that all activities completed (Kirkup et al., 2016). A thorough demonstration from the instructor and availability of peers with whom to collaborate initiates the laboratory work. Accordingly, the laboratory instruction sheet is supported through both student-instructor and student-student interactions.

By contrast, students working in a remote laboratory do not have real-time support from the instructor or laboratory partners. Further, they manipulate the equipment through an internetmediated interface. Therefore, the principal source of support for students is the laboratory instruction sheet. The laboratory instruction sheet for a remote-laboratory experiment will usually contain a modified set of components such as an underpinning theoretical background for the experiment, steps to establish a connection with the equipment, detailed procedures to carry out the experiment and some set tasks to assess learning from the experiment.

In the present study, the laboratory sheet used for remote laboratory experiment did not have a description of the experimental arrangement. Accordingly, students did not learn how to setup the equipment but only how to operate it. This calls for the design review in the present instruction sheet used for remote laboratory, one of the focus areas of this study. This is in marked contrast to face-to-face laboratory work wherein the laboratory instruction sheet encourages and expects students to familiarise themselves with the equipment used and the associated instrumentation. A brief account of the experimental design in both laboratory modes and outline of the associated laboratory instruction sheets that were studied in this article have been provided in Appendix D. 


\section{Conceptual framework: Relationships between student interactions and the laboratory instruction sheet}

The laboratory instruction sheet is an integral component of engineering laboratory learning because it provides a foundation for the student activities and interactions that occur during the laboratory work. Figure 1 is a conceptual framework that shows the relationship between the student undertaking the laboratory and the instruction sheet for the laboratory activity linked via a set of interactions. Thus, in the course of conducting a laboratory, the student may engage in three distinct types of interaction, namely, student-student (S-S) interactions, studentinstructor (S-I) interactions, and student-equipment (S-E) interactions. These interactions then support the student's conduct of the laboratory namely, the laboratory activity, data collection and results analysis that are defined or guided by the content of the laboratory instruction sheet.

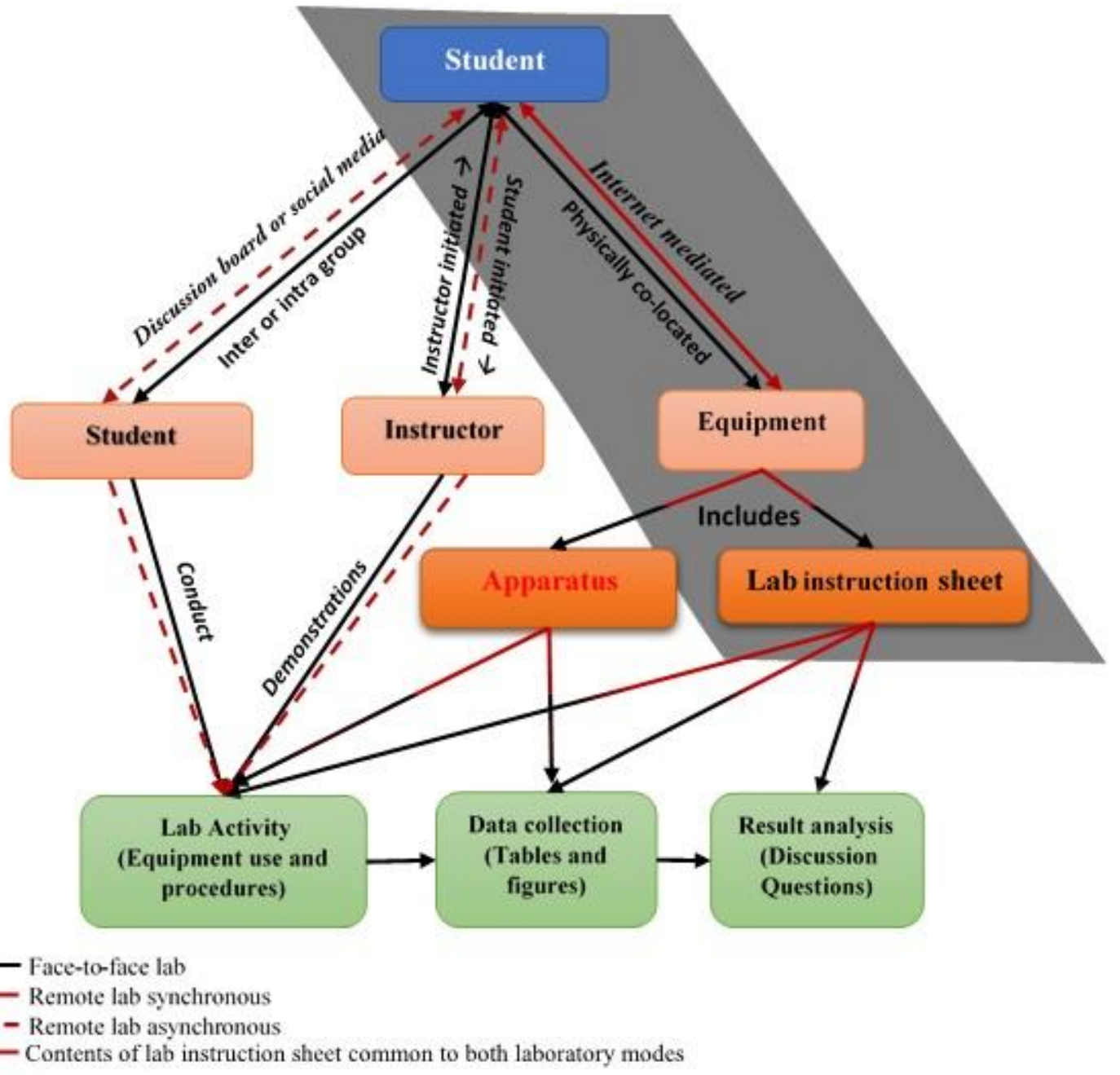

Figure 1: Conceptual framework: the relationship between laboratory instruction sheet and the interaction types in face-to-face as well as remote laboratory modes

In the first of the investigations reported in this paper, the importance of the laboratory instruction sheet as a resource for the student is compared to that of the aforementioned interactions in which the student engages. Thereafter, we focus on the interactions shaded in grey in Figure 1 to contrast student experiences between face-to-face and remote activities because it might be expected that student-equipment interactions would be most affected by the difference in laboratory mode. However, in Figure 1, differences between face-to-face and 
remote-access laboratory modes occur as a result of whether the action link or interaction is synchronous or asynchronous (Heradio et al., 2016; Jara, Candelas, Torres, Dormido, \& Esquembre, 2012). These interactions and their operation in the two modes are expanded upon in the following sub-sections.

\subsection{Interactions occurring in laboratory work}

Three main types of interactions - student-student, student-instructor, and student-equipment have been categorised (Anderson, 2003; Lowe et al., 2012; Moore, 1989; Sher, 2009). The student is the pivotal point in all interaction categories. There is a fourth category, termed indirect interaction, which happens when a student learns or is assumed to learn by observing other students' interactions with their peers or by listening to conversations or discussions occurring either between students or between students and an instructor in the laboratory. Each interaction category makes a distinct contribution to students' laboratory learning (Fila \& Loui, 2014; Lowe et al., 2012; Park, Choe, Schallert, \& Forbis, 2017)[Blinded].

\subsection{Factors affecting the interactions}

The three interactions that occur during laboratory work arise through the activity prescribed in the laboratory instruction sheet. However, there are also important factors that influence the way that the elements - student, instructor, and equipment - interact with each other; these factors are: location, initiation and medium.

Location refers to the arrangements made in which the interactions occur in the laboratory. In the face-to-face laboratory, students, instructors and the equipment are all situated in the same physical facility and share synchronous interaction. By contrast, the only real-time interaction in the remote laboratory is between students and the equipment, this being guided by the laboratory instruction sheet (Ng, 2007; Sonnenwald, Whitton, \& Maglaughlin, 2003) because students remotely access and control real equipment through a web interface.

Initiation relates to interactions between the student and the instructor. It is either instructor initiated or student initiated (Bright et al., 2008; Sher, 2009; Stang \& Roll, 2014). Instructorinitiated interaction mainly takes place during a demonstration of the laboratory activity (most often at its start), whereas student-initiated interaction often takes place when students have difficulties with a laboratory task and therefore seek help from the instructor or have questions that may extend their understanding of the task. When the instructor is physically absent in a remote-access laboratory, initiation can only be due to the student. However, instructor and student initiated interactions can exist in the remote laboratory context when it is mediated by an internet supported platform.

Finally, medium refers to the platform that permits student interaction with the equipment. Students are physically present with the equipment in the face-to-face laboratory, whereas in the remote laboratory student interaction with the equipment is mediated by an internet browser and a user-interface that allow students to establish a connection with and operate the equipment. In the remote laboratory, students interact asynchronously (Corter et al., 2007) with other students and instructors generally on internet-mediated institutional platforms such as discussion boards or social-media platforms such as Skype and Facebook (Heradio et al., 2016; Jara et al., 2012; Jeschke, Pfeiffer, Natho, \& Nsour, 2008).

\subsection{Association between the interactions and the lab instruction sheet}

In engineering laboratories, the laboratory instruction sheet is the most comprehensive source of information for students, providing essential information on the operation of the equipment and its sequencing during the laboratory session. The laboratory activity also has two other 
important components embedded: data collection and results analysis that are related to the laboratory work. These are also guided by the laboratory instruction sheet.

Student-equipment interaction includes interaction with apparatus for its manipulation and also interaction with laboratory instruction sheet. The equipment used and instructions for procedures contained in the laboratory instruction sheet initiates both student-student and student-instructor interactions for manipulating apparatus and all other laboratory-related tasks. In a face-to-face laboratory, student-student interaction may occur between members of the same group or between different groups. The instructor interacts with the students during a demonstration of the laboratory procedures which is based on the laboratory activity described in the laboratory instruction sheet. Student-student and student-instructor interactions further give rise to indirect interactions. The data collection and results analysis information from the laboratory sheet initiates the student-equipment interaction. Thus, in the face-to-face laboratory, the contents of the laboratory instruction sheet influence all four interaction categories described above. By contrast, in the remote laboratory, the instruction sheet directly guides and influences the student-equipment interaction, but it has very limited and indirect influence over the other three categories of interactions, namely student-student, studentinstructor, and indirect interactions. For both laboratory modes, the laboratory instruction sheet contains tables and figures and also discussion questions. These are designed to assist students with data collection and data analysis to arrive at the results that can illustrate or reinforce the concept that the laboratory is designed to impart to the students.

It is important to note that in the face-to-face laboratory all three interactions shown in Figure 1 are inter-related, which then implies that the activities (in the row below) are also interlinked. On the other hand, the remote laboratory provides opportunities for students to work independently and explore all aspects of the experiment but without the opportunity of directly collaborating with peers or seeking guidance from instructors. The sections below specifically report on student's dealing with the laboratory instruction sheet for laboratory related tasks, which indirectly involve students' interaction with all other essential elements of laboratory work discussed above.

\section{Research participants and methodology}

\subsection{Participants}

In the second semester of 2017, 186 engineering students working in a face-to-face laboratory and 37 students performing a remote-laboratory experiment, belonging to two different Australian Universities, were surveyed during their conduct of a laboratory for Engineering Mechanics Unit MCEN1000 and SEB101 [Blinded] respectively. Of the 37 students performing the remote-laboratory experiment, 11 students were from the cohort of 186 students who also undertook the face-to-face laboratory experiment. The student cohorts were in their first year of general Engineering that preceded engineering-discipline specialisation and comprised a range of ethnic backgrounds.

The aforementioned experiments were performed on university premises, the face-to-face in an Engineering laboratory while the remote laboratory was undertaken in a computer laboratory. In both laboratory modes there was an instructor present in the room for demonstration purposes and students worked in small groups (pairs for the remote laboratory) to perform the experiment. The only difference between the two modes was in the direct access to the equipment and the way it was manipulated. This approach was adopted to isolate the impact of remote-access mode by reducing differences arising from other factors and thereby 
increasing the comparability between the two laboratory modes studied regarding studentequipment interactions; see the focus area for this study, shaded in Figure 1.

\subsection{Survey instruments and analysis tools}

The tools mentioned in this article were developed through a pilot study conducted prior to this research and this development of the tools has been discussed in the article [Blind]. The survey tools used in this study have been modified to suit the context of this study.

Pre-laboratory: In order to understand students' perceptions of the importance of the interactions in the laboratory, a pre-laboratory survey was administered prior to the beginning of the laboratory activity. The survey form included four categories: student-student, studentinstructor, student-equipment, and student-laboratory instruction sheet, comprising three items in each sub-category, namely laboratory procedure, clarifying basic concepts and result analysis. The survey form first sought students' demographic information and then asked them to rank the five most important interaction sub-categories in the laboratory according to their perceived importance. Appendix A shows a list of questions in the pre-laboratory survey questionnaire.

Post-laboratory: This survey form was given to students after completion of the laboratory work to understand how students valued each interaction category and elicit their level of satisfaction with each of the interaction categories. The interaction categories were the same as those in the pre-laboratory survey, with the addition of questions on satisfaction with each interaction category and the indirect interaction category. The questionnaire had Likert type questions on a scale from 1 to 10 . The questions from the post-laboratory survey questionnaire for the remote laboratory are shown in Appendix B. Similar questions were designed for the face-to-face laboratory.

Laboratory-instruction Sheet survey: An instrument to seek students' perception of the laboratory sheet in both face-to-face and remote laboratories was developed. This instrument contained questions about aspects related to the laboratory sheet for both laboratory modes. There was an additional open-ended section to allow students to offer their thoughts on improving the current laboratory sheets and also to give additional recommendations for improvements. Appendix C shows the laboratory-sheet survey questionnaire. This survey was given to students after their completion of the laboratory activity.

Analysis tools: SPSS software was used to perform the regression analysis and to calculate correlation coefficients. For qualitative analyses, NVivo 11 was used to conduct a frequency analysis of responses provided by students.

\section{Results}

\subsection{The relative importance of laboratory instruction sheets}

\subsubsection{Pre-laboratory responses}

Students in both laboratory modes were asked to pick and rank the top five most important interactions - seen in the survey form of Appendix A - in the laboratory before they commenced their experiment. In this survey, 'use of the laboratory instruction sheet' was included as a further type of student interaction to those in the first row of Figure 1 in the sense that students can also be thought of as interacting with the laboratory sheet. In particular, we seek to determine the importance of the laboratory instruction sheet relative to the well-established interactions identified and discussed in Section 2 as a resource for undertaking laboratory work. 
Figure 2 compares the students' responses received per item in the pre-laboratory survey in both remote and face-to-face laboratories. In Figure 2, the responses from the students of two different laboratory modes have been overlapped (shown by the white dots with a purple base) and the differences have been shown outlined with a green circle. Within each type of interaction (except Internet Use), the responses are grouped under activities that could be a benefit for the interaction, namely, laboratory procedures (LP), results analysis (RA) and clarification of basic science concepts (BSC).

As shown in Figure 2, for carrying out laboratory procedures, students in both laboratory modes believe that use of the laboratory instruction sheet is the most important. Remote laboratory students thought of it as more useful (by 16\%) compared to those in the face-to-face laboratory. Students do not believe that the laboratory instruction sheet will be important carrying out results analysis with the instructors anticipated to be relied upon for this purpose for students from both laboratory modes. It is noteworthy that the laboratory instruction sheet is seen have the potential to assist students in clarifying basic science concepts at a similar level to that expected from instructors in both laboratory modes; however, it is also noted that this expectation was dominated (by $11 \%$ ) by responses from the students in the face-to-face laboratory. Remote-laboratory students used internet comparatively more (by 15\%) than the face-to-face laboratory students. Figure 2 also indicates generally that the interactions valued most during the laboratory work are directed to laboratory procedures and the analysis of results.

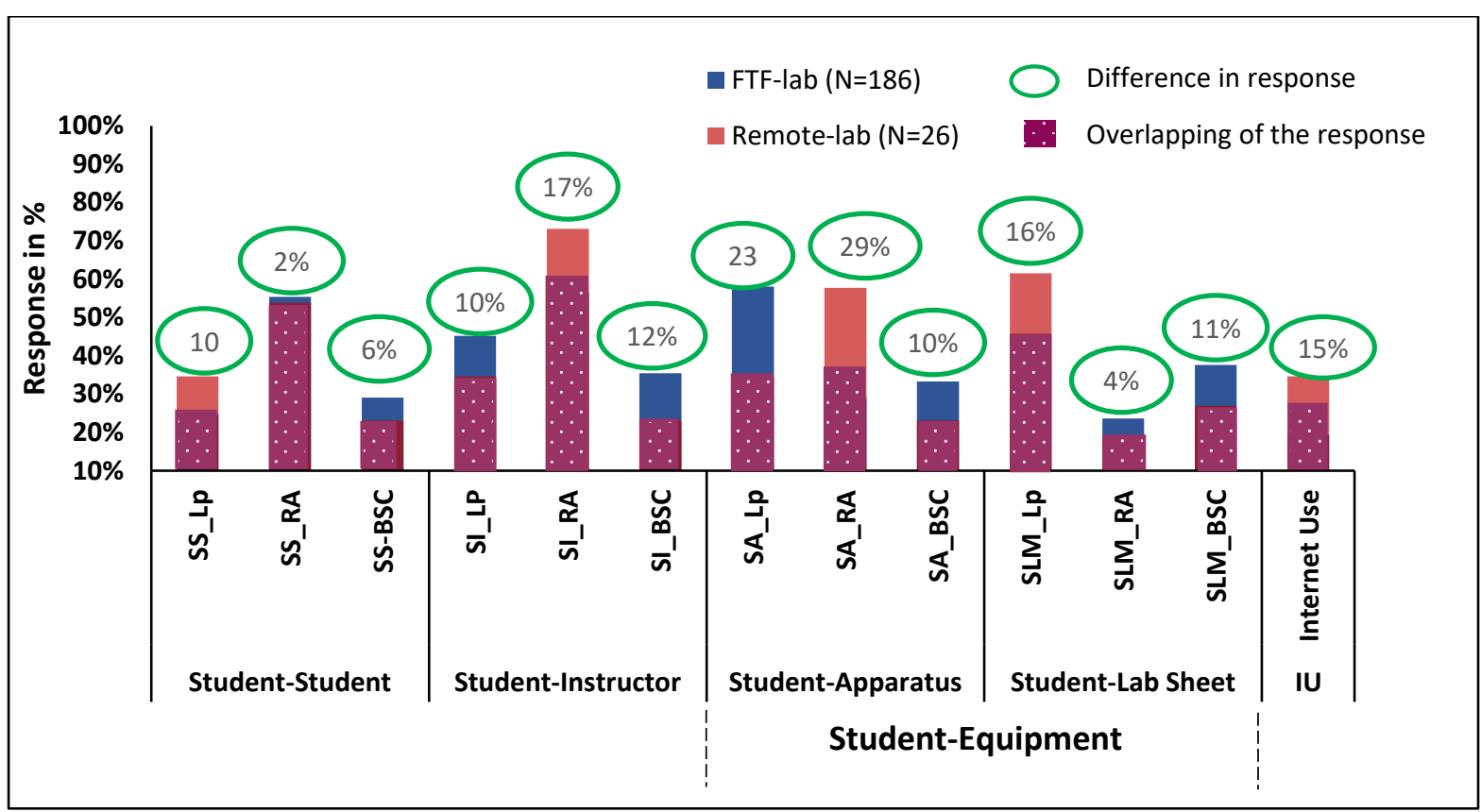

Figure 2. Comparison of the pre-laboratory survey responses in both laboratory modes (FTF = Faceto-face laboratory; _LP = Laboratory Procedures;_RA = Results Analysis; _BSC $=$ Clarification of Basic Science Concepts with interaction type prefix SS = Student-Student, SI = Student-Instructor, SE $=$ Student-Equipment and SLM $=$ Student-Lab [Instruction] Sheet; IU denotes Internet Use). Note that the vertical-axis scale indicates the percentage of students within the cohort who selected the subcategory as one of their five choices.

\subsubsection{Post-laboratory responses}

The post-laboratory survey sought students' perception of the importance of three major interaction categories described above for both laboratory modes. Figure 1 showed that the only synchronous interaction type that is common to both laboratory modes is the student- 
equipment interaction and the initiator of this interaction is the laboratory instruction sheet. We, therefore, focus on the student-equipment interaction in the discussion below. Cronbach's alpha value was calculated to check the internal consistency of the results across all items in the post-laboratory survey. The alpha value for each item was above 0.87 , which indicates that the instrument used for the survey is reliable.

To investigate further, the average of the ratings for the importance (out of 10) for studentequipment interaction items were calculated and compared across the two cohorts studied, that is, face-to-face laboratory users and remote laboratory users. These results are shown in Figure 3. Student-equipment interaction elements are deemed important by students in both laboratory modes. When responses within this category were compared among the two groups of students it was revealed that the remote-laboratory users highly valued the use of the laboratory instruction sheet as well as the manipulation of the equipment (7.86 and 7.82, respectively). On the other hand, students in the face-to-face laboratory considered manipulation of the equipment more valuable than referring to the laboratory sheet for the student-equipment category (6.9 and 8.11, respectively); however, this finding continues to emphasise the importance of the laboratory instruction sheet.

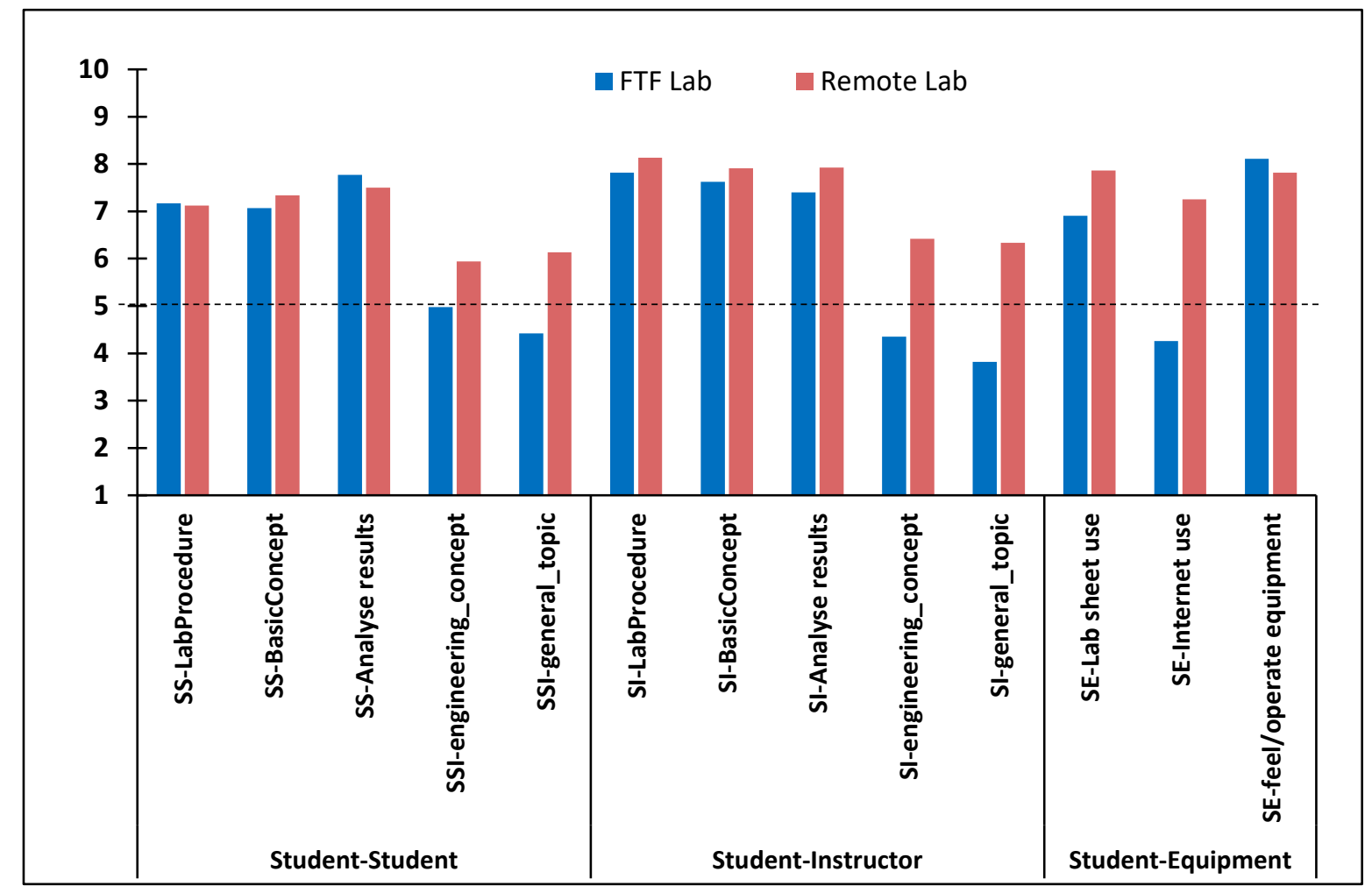

Figure 3: Comparison of the average importance perceived for various interactions (data obtained from the post-laboratory survey of students) (FTF= Face-to-face laboratory)

In addition to judging the importance of the interaction types in the post-laboratory survey, all students were also asked to express their satisfaction for the student-equipment interaction. Responses reveal that the students in the remote laboratory were slightly more satisfied than the students from the face-to-face laboratory. Students working in remote laboratory recorded higher satisfaction (8.03) compared to the face-to-face group (7.23). The relationship between student satisfaction and student-equipment interactions is examined in more detail in Section 5.2 . 


\subsubsection{Summary of the findings regarding Research Questions $R Q 1$ and $R Q 2$}

The laboratory instruction sheet is perceived by students to be the most important resource or source of interaction, for undertaking laboratory procedures, most especially so for remoteaccess, as compared with the instructor and student interactions. However, in the context of student-equipment interactions, remote-access students report that actually operating the equipment is an equally important factor as using the laboratory instruction sheet. In other words, in remote-access mode, students tended to experiment with equipment more than reading the laboratory instruction sheet.

\subsection{Effects of the laboratory instruction sheet on students' satisfaction}

By merely reviewing the survey responses it is difficult to predict influence of one factor on the satisfaction expressed for student-equipment interaction. Accordingly, in order to explore the reasons for items within the student-equipment interaction category that influenced students' satisfaction, statistical analyses was conducted. For the face-to-face laboratory, regression analysis was performed. The total response received from the face-to-face laboratory group was divided into two equal groups of approximately $50 \%$. This was done primarily to develop a regression model using the first $50 \%$ of the data and then validate the model with the remaining 50\%. By contrast due to the fewer participants $(\mathrm{N}=37)$ in a remote laboratory, no attempt to perform a regression analysis was made, but instead, correlation coefficients were calculated. The results for these analyses are as follow.

\subsubsection{Face-to-face laboratory}

For the face-to-face laboratory, a stepwise multiple regression analysis (Tabachnick \& Fidell, 2013) was performed to predict the student's satisfaction based on their use of laboratory sheet, the operation of the equipment and the use of the internet for performing the experiment; i.e. the activities within the student-equipment grouping of Figure 3.

Student satisfaction was considered as the dependent variable and the other three variables: use of laboratory instruction sheet, the operation of the equipment and the use of internet were used as the predictor variables. For both the sample groups, the variable that contributed most significantly was entered first in the calculation followed by the variable that was the second significant contributor but at the same time had its F-statistic value greater than 0.05.

Calculations revealed that use of the internet when conducting the experiment had no significant contribution in student satisfaction for the student-equipment interaction while the use of the laboratory sheet and the operation of the equipment demonstrated did. Therefore, the results have been presented only for use of laboratory sheet and the operation of the equipment.

Table 1 contains the regression coefficients obtained for both groups of data. The table further shows that both the predictor variables, use of laboratory instruction sheet and the operation of the equipment, were significantly associated with the students' satisfaction with the studentequipment interaction. In the first sample, the association was $\left(\mathrm{R}^{2}=0.316, \mathrm{p}>0.01\right)$ and for the second sample the association increased slightly $\left(\mathrm{R}^{2}=0.313, \mathrm{p}>0.01\right)$. 
Table 1: Model summary for student-satisfaction as dependent variable

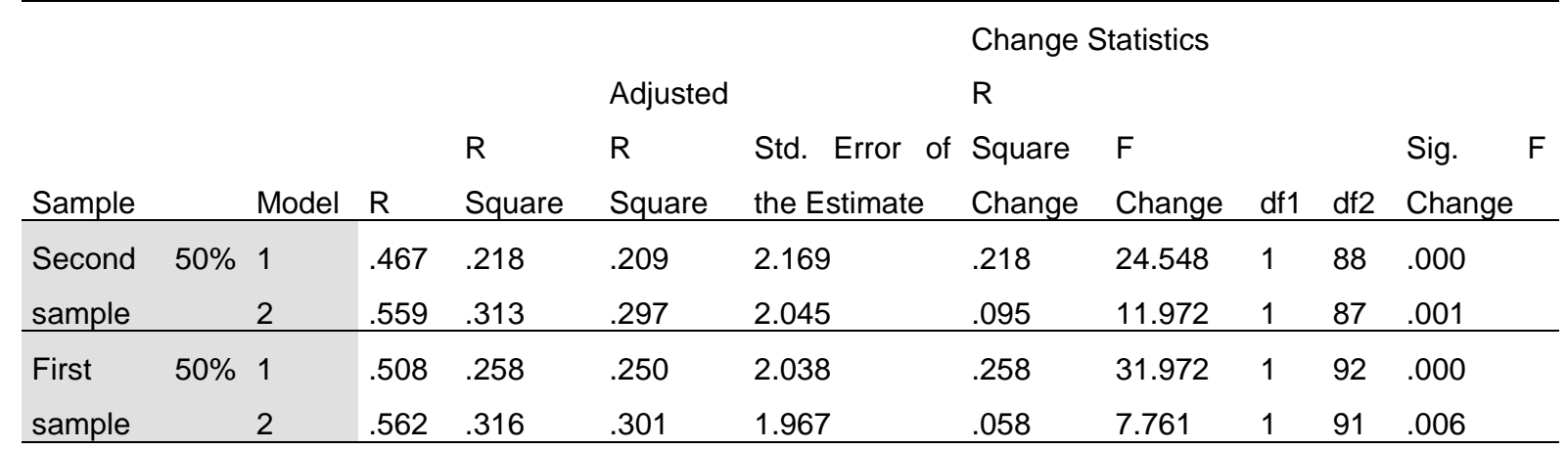

Table 2 shows that the beta coefficients for the operation of equipment and use of laboratory sheet when examined separately using both sample groups were positive and significant, $(b=0.467, p<0.01)$ and $(b=0.508, p<0.01)$ respectively. Further, when both variables were considered together in the two sample groups, it was again found that the beta coefficients for both variables were positive and significant. In the first $50 \%$ sample, it was $(b=0.268, p<0.01)$ and $(b=0.391, p<0.01)$ respectively for operation of the equipment and the use of laboratory sheet. Similarly, in the second sample group it was $(b=0.349, p<0.01)$ and $(b=0.330, p<0.01)$ respectively.

Table 2: Model coefficients - student satisfaction as dependent variable

\begin{tabular}{|c|c|c|c|c|c|c|c|}
\hline \multirow[t]{2}{*}{ Sample } & \multirow{2}{*}{\multicolumn{2}{|c|}{ Model }} & \multicolumn{2}{|c|}{$\begin{array}{l}\text { Unstandardized } \\
\text { Coefficients }\end{array}$} & \multirow{2}{*}{$\begin{array}{l}\text { Standardized } \\
\text { Coefficients } \\
\text { Beta }\end{array}$} & \multirow[t]{2}{*}{$\mathrm{T}$} & \multirow[t]{2}{*}{ Sig. } \\
\hline & & & $B$ & $\begin{array}{l}\text { Std. } \\
\text { Error }\end{array}$ & & & \\
\hline \multirow{5}{*}{$\begin{array}{l}\text { Second } \\
\text { sample }\end{array}$} & \multirow{2}{*}{1} & (Constant) & 3.052 & .881 & & 3.466 & .001 \\
\hline & & Operate equipment & .535 & .108 & .467 & 4.955 & .000 \\
\hline & \multirow{3}{*}{2} & (Constant) & 1.858 & .899 & & 2.066 & .042 \\
\hline & & Operate equipment & .399 & .109 & .349 & 3.659 & .000 \\
\hline & & Use of lab sheet & .329 & .095 & .330 & 3.460 & .001 \\
\hline \multirow{5}{*}{ First $50 \%$ sample } & \multirow{2}{*}{1} & (Constant) & 3.498 & .688 & & 5.085 & .000 \\
\hline & & Use of lab sheet & .535 & .095 & .508 & 5.654 & .000 \\
\hline & \multirow{3}{*}{2} & (Constant) & 1.268 & 1.040 & & 1.219 & .226 \\
\hline & & Operate equipment & .370 & .133 & .268 & 2.786 & .006 \\
\hline & & Use of lab sheet & .412 & .101 & .391 & 4.063 & .000 \\
\hline
\end{tabular}

Based on these results, we found that for both the variables, the operation of equipment and the use of laboratory instruction sheet had a significant association with the students' satisfaction with the student-equipment interaction. Considering the beta coefficients of the two predictor variables when observed separately, it can be concluded that the use of laboratory instruction sheet was a relatively better predictor of student satisfaction for the student-equipment interaction.

\subsubsection{Remote laboratory}

Assessment of the correlations between the three items under the student-equipment interaction in Figure 3 and the satisfaction for this interaction type showed that use of the laboratory sheet for conducting the experiment was significantly correlated with the feel of performing a real experiment $(\mathrm{r}=0.588, \mathrm{p}<0.01)$, which further had significant a correlation with the student satisfaction for the student-equipment interaction $(r=0.546, p<0.01)$. However, there was no 
direct significant correlation between the use of the laboratory instruction sheet and student satisfaction for the student-equipment interaction.

\subsubsection{Summary of the findings regarding Research Question RQ3}

For the face-to-face mode, the importance of the laboratory sheet correlates directly with student satisfaction but for remote-access, this is not evident. However, it is indirectly linked via student satisfaction with the operation of the equipment; this perhaps suggests that students will comfortably 'learn by operating the equipment' without the need for instructions because they do not fear to damage the equipment (Vuthaluru et al., 2013) and its immediate repercussions that would be the case in a face-to-face laboratory. Accordingly, use of the laboratory instruction sheet in the remote-laboratory mode does play a role in providing students with the feeling of working in a real hands-on laboratory. Similar findings has been reported in the work conducted by Jona et al. (2011).

\subsection{Student needs in the design of laboratory instruction sheets}

The foregoing results have demonstrated that the laboratory instruction sheet is an important resource that should be carefully designed when developing laboratory learning activities. In this section, we primarily address research questions RQ4 and RQ5, the answers to which serve to inform the design of laboratory-instruction sheets.

Accordingly, we now present the results of an investigation that serves to identify, from a student perspective, the factors that may underpin the appropriate design of effective laboratory instruction sheets. In particular, we focused on whether its design might be dependent upon the laboratory mode and/or the level of students' abilities in the overall subject of which the laboratory comprises a part of the curriculum. Thus, a further survey, that was designed to elicit students' views on the levels at which different aspects of the laboratory activity were aided by the instruction sheet, was conducted using the same groups as those in Sections 5.1 and 5.2. A total of 150 responses were received from students who had completed the laboratory.

A further question in the survey requested that students identify their satisfaction with the laboratory instruction sheet that they used. In addition, students were also invited to give suggestions for improvement of the laboratory instruction sheet through a set of open-ended questions that pertained to a different aspect of the laboratory activity (see the full questionnaire in Appendix C).

\subsubsection{Dependence upon laboratory mode: face-to-face versus remote-access}

\subsubsection{Students' agreement with the effectiveness of instruction sheet}

Figure 4 shows the first-year-student responses from face-to-face and remote laboratories. In the main, students selected agreement with the item statements in the questionnaire (see Appendix C) and therefore Figure 4 shows only students' agreement or strong agreement for the items in the survey.

Contrasting the results between face-to-face and remote laboratory modes indicates that students in the remote mode were less inclined to read the laboratory instruction sheet or rely upon it for procedural aspects of the laboratory activity (75\% agreement compared with $86 \%$ agreement for the face-to-face mode students). This may suggest that in the remote-mode students were more inclined to 'discover' how to use the equipment through operating it while the face-to-face students felt it necessary to follow given instructions lest the equipment in front of them was damaged (Vuthaluru et al., 2013). However, the remote-laboratory students 
expressed greater engagement with the instruction sheet for understanding the concepts explored by the laboratory activity ( $81 \%$ agreement compared to 59\% agreement for the faceto-face mode students). This may arise from a greater reliance on the written explanation of concepts than that for the face-to-face students who could also obtain such understanding by interacting with other students and/or the laboratory instructor. Nevertheless, the remote-mode students showed a lower level of agreement on the statement that asked whether all of the necessary information was contained in the instruction sheet (60\% agreement compared with $88 \%$ agreement for the face-to-face mode students). This result may suggest that they had accessed other sources of (online) information to supplement their understanding of the activity whereas the face-to-face students undertook the activity expecting to use only the instruction sheet and their instructor as the resources needed to complete the activity.

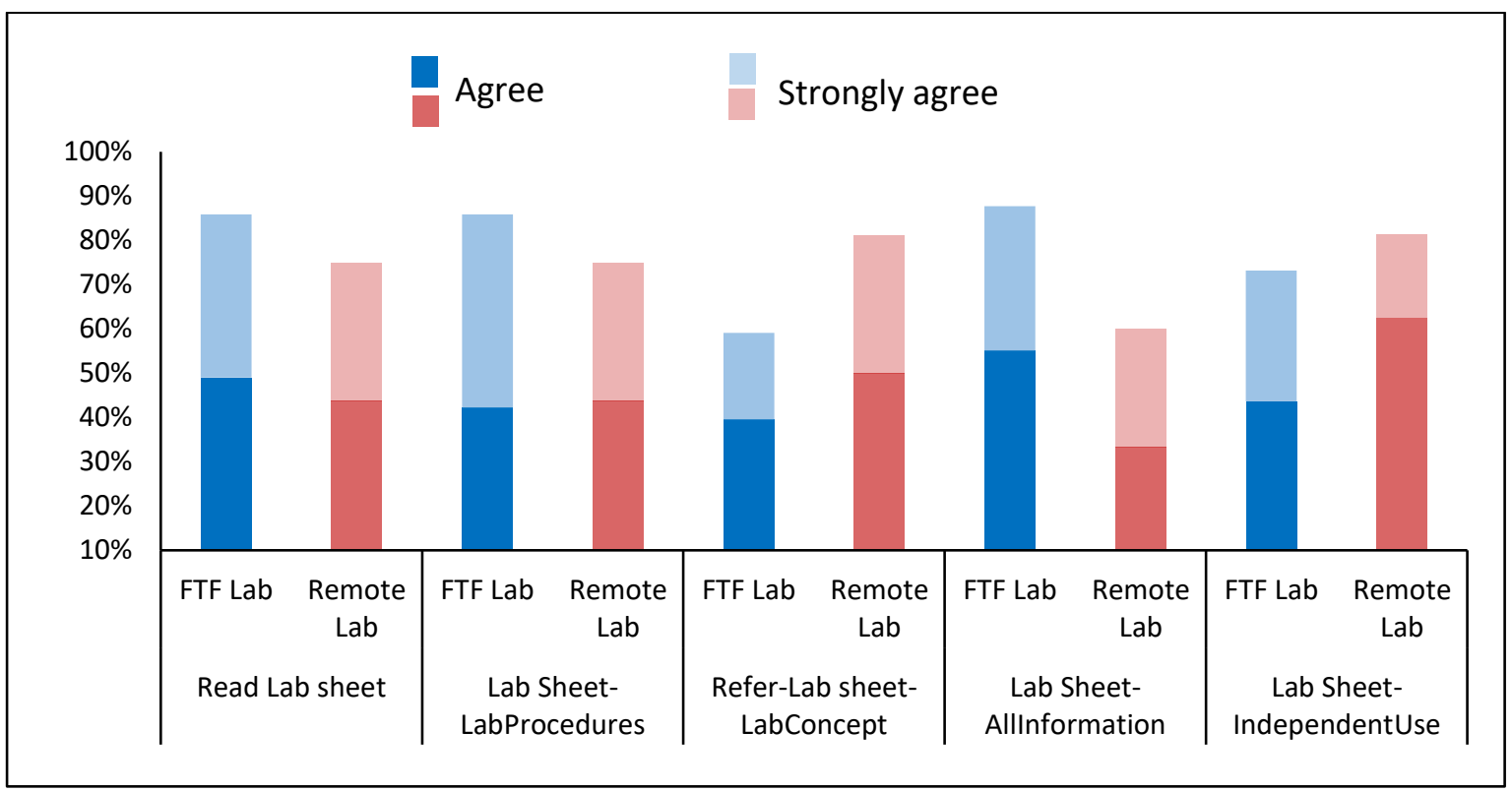

Figure 4: Student levels of agreement with various aspects indicating the usefulness of the laboratory instruction sheet: comparison of FTF (face-to-face) and remote modes. $\mathrm{N}$ for FTF= 150 and $\mathrm{N}$ for remote lab $=16$

Finally, both cohorts showed high levels of agreement with the statement that the laboratory sheet enabled them to undertake the laboratory activity independently, with the remote-mode students at a slightly higher level of agreement, as might be expected given that it was the only resource provided to them, (with $81 \%$ agreement compared to $74 \%$ agreement for the face-toface mode students). Responses to the question on satisfaction (not plotted in Figure 4) showed that the remote-mode students reported a similar level of satisfaction with the content of the instruction sheet as the face-to-face mode students (with $87.5 \%$ agreement compared to $86 \%$ agreement for face-to-face mode students). This appears to contradict their view that, relative to the view of students in the face-to-face mode, the instruction sheet did not contain all the information required to complete the laboratory. Again, this result may indicate that the remotemode students were unafraid to use other sources of information to help them undertake the activity.

\subsubsection{Student opinion on the importance of the instruction sheet}

In order to understand the quantitative comparison above, a number of students who conducted both the face-to-face laboratory and the corresponding remote-laboratory activity were 
randomly selected and asked about their perceptions of the laboratory instruction sheet they used for performing the experiment online; below are some of the responses received.

"That would make the instructor obsolete whereas in the physical labs that we've done we kind of needed the instructor"

"if it's a remote project there will be a much more condensed manual.... and that would help you more"

"Well generally reading through the lab material itself and also the sort of material that comes with the lectures, which only prepares you as much as you need to really"

"I feel like the instructor's almost a fall back. Like 90\% of the time I can understand it just from the book but if I don't understand it from the book then like I need someone to explain it"

“....you don't necessarily need a tutor [instructor] because if you can do it online and there is a clear instruction online of how to do it, that's pretty much the only thing that I get from tutors usually during the lab"

Overall, the qualitative responses indicate that students considered the laboratory instruction sheet to be sufficient for carrying out the laboratory work if the laboratory instruction sheets are well designed (Braun et al., 2018; Nikolic et al., 2015). They were, therefore, suggesting that to perform activities in the remote laboratory setting, students only required the laboratory instruction sheet and access to operate the equipment. Such statements indicate that there needs to be a higher level of care in preparing the laboratory instruction sheet for remote laboratory work. The sheet should be comprehensive and effective enough to establish an authentic connection experience for students working in a remote laboratory. This may seem a little contradictory to the qualitative results of Figure 4 and the student-satisfaction levels that appeared to indicate that, in the absence of a completely comprehensive instruction sheet, students undertaking the laboratory remotely were able to complete the laboratory by, presumably, accessing other materials that supported their completion of the laboratory.

\subsubsection{Dependence upon student achievement}

To determine whether students' levels of agreement with the different aspects of the laboratory instruction sheet might also depend upon student achievement, the same data for the face-toface laboratory students used to generate Figure 4 were grouped according to their final grades in the unit (the total mark for the unit was 100) into four groups: unsuccessful (below 50), low achievers (50-60), moderate achievers (61-75), and high achievers (75 and above). A similar breakdown of the cohort was not possible for the remote-laboratory students due to the small number of participants. The results of this investigation are presented in Figure 5.

It is evident from Figure 5 that there are both similarities and differences in the response patterns across the low, moderate, and high achieving groups. The level of agreement for usage of laboratory sheet for the laboratory procedures is similar across all groups with the slightly stronger agreement coming more from the low achieving groups. 


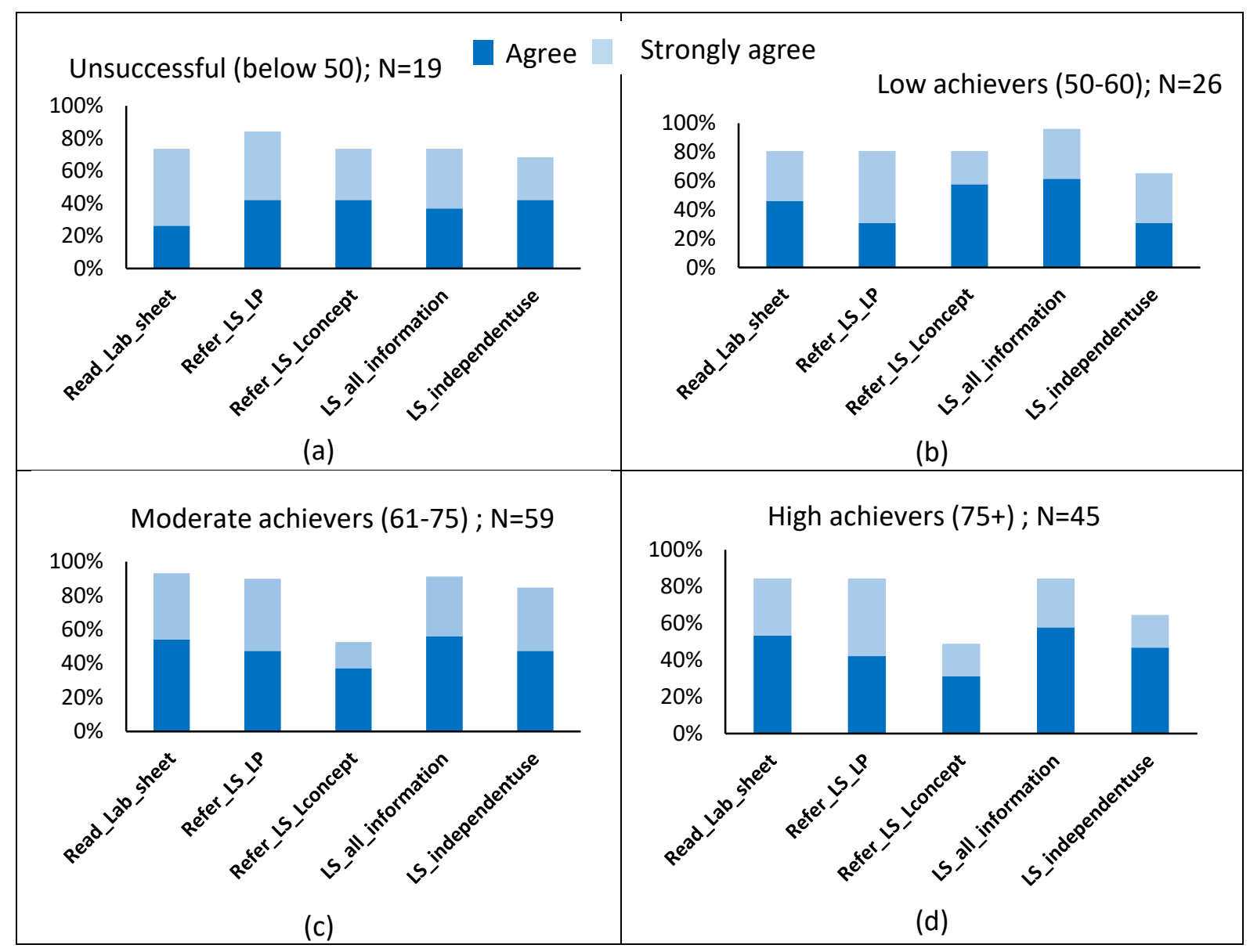

Figure 5: Face-to-face laboratory students' responses to the utility of the laboratory instruction sheet categorised on the basis of student achievement in the practical examination

1 The low-achieving group clearly seem to rely on the laboratory sheet for understanding 2 conceptual matters related to the laboratory work as compared with the moderate and high 3 achieving groups; this suggests that more able students apply understanding gained from the 4 lecture-based components of their studies to the laboratory. It is also noteworthy that for 5 independent conduct of the laboratory work using the instruction sheet, the moderate achievers 6 showed higher agreement with the statement than both the low- and high-achieving groups. It 7 might be speculated that the low-achieving group relied heavily on the instructor to enable 8 them to complete the activity while the high-achieving group used the instructor's expertise to 9 maximise their understanding of the laboratory work.

10 Responses to the question on students' level of overall satisfaction with the content of the instruction sheet (data not presented here) showed that the low and moderate achievers indicated slightly higher satisfaction than the high-achieving group. This finding may suggest that high-achieving students will always seek further information to advance their knowledge and performance levels. Conversely, this suggestion may be reinforced by the fact that lowachieving groups showed comparatively greater agreement to the item about the laboratory sheet containing all related information for the laboratory work.

17 Finally, the first group in Figure 5, who did not secure pass marks in their practical examination have an almost similar level of agreement for all items. 


\subsubsection{Students' suggestions for improvement in the laboratory instruction sheet}

The foregoing results show that there were varying responses to the information content, conceptual content and overall satisfaction with the laboratory instruction sheet from students in both laboratory modes. As this was predicted during the design phase of the questionnaire, sections seeking suggestions for the improvement in the laboratory-instruction sheet were included (as optional) in the questionnaire (see Appendix C). Thus, questions were included in seeking suggestions on improvements in the areas of conceptual content, instructions for carrying out the laboratory work and finally the data collection and analysis of results. Suggestions and comments received from students in the face-to-face and remotely controlled laboratory modes are respectively reported as follows.

\subsubsection{Suggestions for the face-to-face laboratory instruction sheet}

A qualitative analysis of the responses was conducted using NVivo 11 software to look for repetitions in the suggestions. Under the three sections mentioned above, we further grouped the repeated suggestions. The most common suggestions for each section are as follows.

For the theoretical concept section, there were comments which said that there should be a more detailed theory with a better explanation of the equations used. Further stress was given by stating that the theory presented should be easy to understand. Some suggested that the inclusion of diagrams for better explanation of the theory could enhance students' work in the laboratory.

Similarly, for the laboratory procedures section, although the content was considered good enough that it required no further additions, there were some suggestions which said that the instructions needed to be more detailed and should have more images and diagrams for a better understanding of the procedures. Further supplementing comments said the instructions on the laboratory sheet should be very specific and concise.

For the data collection and results analysis section, students, in pursuit of a higher level of performance, suggested providing better graphs than those that were given in the laboratory sheet, while others wished for clearer tables for data collection. A few students expressed difficulty in collecting data from the experiment or analysing their results, stating that the laboratory sheet needed to have better instructions for collecting the data and then analysing them for the desired results.

\subsubsection{Suggestions for the remote-laboratory instruction sheet}

Students' suggestions for improving the laboratory sheet in the remote laboratory experiment was to some extent similar to the suggestions received for the face-to-face laboratory instruction sheet. As the two laboratory modes have different modes of performing the experiment, some of the suggestions reflected that difference. For instance, students suggested putting guidelines in the laboratory sheet for ways to download the files containing their data obtained during their experiment and also mentioning whether an external drive needed to be brought to the laboratory session.

Students in the remote laboratory also suggested that videos be used to illustrate the procedures related to laboratory work and also for the theoretical aspect of the experiment. Some suggested that in addition to the laboratory procedures, it would be good if there was a brief description of the phenomena or changes that were taking place in the equipment when instructions were given from the computer interface. They believed that this would give them foreknowledge about what they were expected to do and also whether they were noticing the right observables 
on the screen. There was also a suggestion regarding guidance for writing the report which they thought was missing.

\subsubsection{Summary of the findings regarding Research Question RQ4 and RQ5}

The design of the laboratory-instruction sheet has been shown to be dependent upon both the mode in which the laboratory is undertaken and, for the face-to-face mode, the ability of the student. In the former regard, remote-mode students appear to place less reliance on the instruction sheet than those students in the face-to-face laboratories. This difference may be because the remote laboratory students are prepared to access other sources of online information while the face-to-face students largely depend upon the instruction sheet and the expertise of the instructor who is effectively absent in remote-access work. With regard to the influence of student ability on the needs of the instruction sheet, the main finding is that lowerachieving students place greater reliance on the instruction sheet than high-achieving students. The most striking student suggestion for improving the laboratory instruction sheet in remote mode concerned the use of video (presumably hyperlinked from the sheet) for both procedural and conceptual aspects of the activity; this would be a natural extension of the activity-delivery platform. This also applies to face-to-face laboratories, that is, if students can read the laboratory instruction from an electronic device such as tablets or computers, it certainly can enhance students' interest and hence their work in the laboratory. One such work in this context can be found in Patterson (2011).

\section{Limitations and Discussion of overall findings}

The laboratory instruction sheet is generally viewed by students to provide all the basic information required for conducting the experiment, namely: a background or description of the concepts to be reinforced by the experiment, detailed procedural guidelines and the opportunity to validate the understanding of the laboratory work. This is true for students in both face-to-face and remote laboratories. The laboratory instruction sheet for the remote laboratory contains additional information regarding the establishment of the connection with the equipment which is remotely situated from the students. From the model of relationships between the interactions and the laboratory instruction sheet, shown in Figure 1, it can be ascertained that the basis for all interactions related to laboratory work is underpinned by the laboratory instruction sheet.

The investigations made in this article are based on small cohort of students who worked on a remotely-accessed laboratory experiment. Remote laboratory experiments are not widely available in Australian institutions, and those that do have fewer students who opt to work in this of mode of laboratory. Experimenting the effectiveness of remote laboratories with small cohorts and then to later introduce them to a larger group has remained the focus of educators who foresee a greater advantage of this mode. Also, because this study only reports on the students' perceptions from the first-year undergraduate engineering degrees, it would be significant at a later point to compare the findings of this study with the perceptions of students from senior years of an undergraduate engineering degree.

In the remote laboratory, students are bound to rely on the laboratory instruction sheet to perform their work due to the absence of the real-time support of instructors and laboratory partners. Satisfaction with the student-equipment interaction was reported by students to be higher among the remote laboratory groups from both institutions as compared with the faceto-face laboratory users. This is perhaps surprising given the absence of the element of physical touch and sense of the equipment and its behaviours as it is manipulated. However, the differences in satisfaction level scores were only marginal and thus the similarity in scores may 
be due to the fact that the laboratory experiment considered in this study was relatively simple (a bending beam) and therefore there was little difference in its observed behaviour between the two modes. A more complex piece of equipment, for example rotating machinery, may offer limited or restricted viewing of its behaviour in remote access mode as compared to its observation in the proximity of a face-to-face laboratory. Furthermore, the presence of an instructor/invigilator and other students in the remote laboratory set-up used in this study may have eased conduct of the laboratory task which led to better satisfaction.

As every interaction type makes its own distinct contribution to student learning and is guided by the laboratory sheet, effort needs to be made to preserve the learning that is gained from each interaction, at least to some extent. Design of the laboratory instruction sheet should be based on the interactions that are possible to synchronise in a particular laboratory mode. For instance, in the face-to-face laboratory, all interactions are synchronous so the laboratory instruction sheet can simply be modified to improve the quality of its contents. By contrast, in the remote laboratory, changes in the design of the laboratory sheet could address the missing interactions of the student with instructors and peers, who respectively provide support with the demonstration of the experiment and carrying out of the experiment. Clearly, the fact that the remote laboratory is enabled by the internet means that further online extensions to the traditional (document-based) laboratory briefing sheet could achieve this.

The design of effective laboratory-instruction sheets also seems to be dependent upon to the ability of the student undertaking the activity. The variation of such needs is more difficult to accommodate in a traditional document-based briefing sheet - usually written in a linear mode of exposition - that would become unwieldy if to cover all possible student needs. By contrast, in remote-laboratory work, an online briefing sheet is better suited to a design that includes links to additional online materials (that may include video explanations) so that students can follow an exposition pathway suited to their particular needs and abilities.

\section{Conclusions}

The laboratory-instruction sheet has been shown to be an integral part of laboratory work for both face-to-face and remote laboratories. The quality and depth of information in the laboratory instruction sheet can have an effect on the way in which students perceive the importance of their various interactions that occur in either laboratory mode. This perception further influences the students' satisfaction with the laboratory work performed as a result of the interaction with the equipment.

The results from the pre-laboratory survey revealed that before commencing the laboratory experiment, students in both laboratory modes considered the laboratory-instruction sheet to be the most important resource for undertaking the laboratory procedures. For face-to-face laboratory students, it plays a similar role as instructors for the clarification of the basic concepts related to laboratory activity. Students in remote as well as in face-to-face laboratories did not expect to make much use of the laboratory instruction sheet for the purpose of analysing their results.

After the conduct of the actual experiment, there remained similarities across the two laboratory modes in students' responses to the importance of the different interactions experienced in the laboratory. This study then focused on the relationship between laboratory instruction sheet and student-equipment interaction, the post-laboratory response analysis showing that there was substantial reliance upon the laboratory-instruction sheet by students in both laboratory modes when interacting with the equipment. The laboratory instruction sheet 
also significantly affected students' satisfaction of the student-equipment interaction in the face-to-face laboratory, while in the remote laboratory setup it made a significant contribution to providing students with the feel of performing a real experiment leading to comparatively greater satisfaction for student-equipment interaction.

Students' perception of the laboratory instruction sheet for the remote laboratory indicated that a well-designed laboratory instruction sheet has the potential to effectively replace an instructor or a laboratory partner in terms of successfully completing the activity. A qualitative investigation of students' views of the laboratory sheet suggested that students perceive some modifications in the laboratory instruction sheet in all its major areas in order to achieve better learning outcomes from the laboratory work.

The main findings of this study can be summarised as follows. The laboratory sheet:

- Is perceived by students to be very important for procedural aspects of laboratory work but students undertaking remotely-operated laboratories find that actually operating the (remote) equipment can meet this need;

- Is a contributing factor to student satisfaction in face-to-face laboratory work but less important for student satisfaction in remote-access laboratories, although it plays an important role in giving students the feel that they are conducting a 'real' experiment; and

- Should meet different content requirements and emphases that depend upon the laboratory mode and perhaps should be tailored to, or at least recognise, different levels of student academic ability.

The overall outcome of the paper is that the laboratory instruction sheet is comparatively less important for effective learning in remotely accessed laboratory work. This may be because students are less fearful of damaging equipment that is not physically co-located and therefore more likely to learn by 'experimentation' as opposed to following procedures. On the one hand, free experimentation is an ideal way to learn but on the other hand engineering students must, through the course of their studies, learn how to interpret, respect and adhere to operating procedures for equipment because graduate engineers do not play (experiment) with expensive and sometimes dangerous equipment in their post-university workplace.

This study has only considered the development of technical and analytical skills, based on theoretical concepts, through laboratory learning. The design of laboratory-instruction sheets for remote laboratories should also promote or preserve the learning outcomes of face-to-face laboratories that include the tacit development of personal and professional engineering skills that are most often inculcated through the student-student and student-instructor interactions. This aspect of laboratory learning remains a topic for future studies.

\section{Disclosure Statement}

The authors declare no conflicts of interest.

\section{Funding}

This work was supported by the Australian Research Council [Grant number DP140104189]. 


\section{References}

Anderson, T. (2003). Getting the mix right again: An updated and theoretical rationale for interaction - ProQuest. International Review of Research in Open and Distance Learning, 4(2). Retrieved from http://search.proquest.com.libproxy.wlu.ca/docview/1634543750/abstract/12BC66AB86 434899PQ/1?accountid=15090

Braun, M., Kirkup, L., \& Chadwick, S. (2018). The impact of inquiry orientation and other elements of cultural framework on student engagement in first year laboratory programs. International Journal of Innovation in Science and Mathematics Education, 26(4), 3048.

Bright, C., Lindsay, E., Lowe, D., Murray, S., \& Liu, D. (2008). Factors that impact learning outcomes in both simulation and remote laboratories. ED-MEDIA 2008--World Conference on Educational Multimedia, Hypermedia \& Telecommunications, 62516258. Retrieved from http://www.editlib.org/p/29248

Coppens, P. (2016). Engineering technology students 'activities and learning in an electronics laboratory. The Katholieke Universiteit Leuven.

Corter, J. E., Nickerson, J. V., Esche, S. K., Chassapis, C., Im, S., \& Ma, J. (2007). Constructing reality: A study of remote, hands-on and simulated laboratories. ACM Transactions on Computer-Human Interaction, 14(2), 7-es. https://doi.org/10.1145/1275511.1275513

Couteur, P. Le. (2009). Review of literature on remote \& web-based science labs, 1-22. Retrieved from http://www.nic.bc.ca/pdf_docs/carti/Review_of_Literature_on_Remote_and_Webbased_Science_Labs.pdf

Craven, K. K. (2003). Assessing the effectiveness of a project-based laboratory manual for a c programming course. In American Society for Engineering Education (p. 8.242.18.242.9).

Fila, N. D., \& Loui, M. C. (2014). Structured pairing in a first-year electrical and computer engineering laboratory: The effects on student retention, attitudes, and teamwork *. International Journal of Engineering Education, 30(4), 848-861.

Gregory, S. J., \& Di Trapani, G. (2012). A blended learning approach to laboratory preparation. International Journal of Innovation in Science and Mathematics Education, 20(1), 56-70. Retrieved from http://www.scopus.com/inward/record.url?eid=2-s2.084865544956\&partnerID=40\&md5=69e486f7c567ec96dbf65d0a4ae45541

Heradio, R., De La Torre, L., Galan, D., Cabrerizo, F. J., Herrera-Viedma, E., \& Dormido, S. (2016). Virtual and remote labs in education: A bibliometric analysis. Computers and Education, 98, 14-38. https://doi.org/10.1016/j.compedu.2016.03.010

Högström, P., Ottander, C., \& Benckert, S. (2010). Lab work and learning in secondary school chemistry: The importance of teacher and student interaction. Research in Science Education, 40(4), 505-523. https://doi.org/10.1007/s11165-009-9131-3

Hou, G., Zhong, F., \& Ayala, O. M. (2017). Manual revision process for project-based laboratory instruction. In ASEE Annual Conference and Exposition, Conference 
Proceedings (Vol. 2017-June, pp. 1-17).

Jara, C. A., Candelas, F. A., Torres, F., Dormido, S., \& Esquembre, F. (2012). Synchronous collaboration of virtual and remote laboratories. Computer Applications in Engineering Education, 20(1), 124-136. https://doi.org/10.1002/cae.20380

Jeschke, S., Pfeiffer, O., Natho, N., \& Nsour, J. (2008). Classroom-laboratory interaction in an electronic engineering course. In International conference on Innovations in information technology (pp. 3-7). https://doi.org/10.1109/INNOVATIONS.2008.4781664

Jona, K., Roque, R., Skolnik, J., Uttal, D., \& Rapp, D. (2011). Are remote labs worth the cost? Insights from a study of student perceptions of remote labs. International Journal of Online Engineering, 7(2), 48-53. https://doi.org/10.3991/ijoe.v7i2.1394

Kirkup, L., Varadharajan, M., \& Braun, M. (2016). A comparison of student and demonstrator perceptions of laboratory- based, inquiry-oriented learning experiences. International Journal of Innovation in Science and Mathematics Education, 24(2), 1-13.

Lang, J. (2012). Comparative Study of hands-on and remote physics labs for first year university level physics students. Transformative Dialogues: Teaching \& Learning Journal, 6(1), 1-25.

Lindsay, E., \& Good, M. (2005). Effects of laboratory access modes upon learning outcomes. IEEE Transactions on Education, 48(4), 619-631. https://doi.org/10.1109/TE.2005.852591

Lowe, D., Murray, S., Li, D., \& Lindsay, E. (2012). Remotely accessible laboratories enhancing learning outcomes. Australian learning and teaching council. https://doi.org/10.1109/REV.2012.6293111

Ma, J. (2006). Collaboration Processes in Hands-on and Remote Labs (p. 11). Retrieved from https://pdfs.semanticscholar.org/e072/7f64065c9e5c7f4f52efb2d293781e9106b0.pdf

Ma, J., \& Nickerson, J. V. (2006). Hands-on, simulated, and remote laboratories: A Comparative Literature Review. ACM Computing Surveys, 38(3), 1-24. https://doi.org/10.1145/1132960.1132961

Machotka, J., \& Nedic, Z. (2006). The remote laboratory netlab for teaching engineering courses. Global Journal of Engineering Education, 10(2), 205-212.

Mahmood Khan, Z., \& Alghazzawi, D. (2011). Improved laboratory manual designs: In accordance with system development life cycle for logic building and algorithm designs. In 2011 3rd International Congress on Engineering Education: Rethinking Engineering Education, The Way Forward, ICEED 2011 (pp. 76-79). https://doi.org/10.1109/ICEED.2011.6235364

Maldarelli, G. a., Hartmann, E. M., Cummings, P. J., Horner, R. D., Obom, K. M., Shingles, R., \& Pearlman, R. S. (2009). Virtual lab demonstrations improve students' mastery of basic biology laboratory techniques. Journal of Microbiology \& Biology Education, 10(May), 51-57. https://doi.org/10.1128/jmbe.v10.99

Moore, M. G. (1989). Three types of interaction. American Journal of Distance Education, 3(2), 1-7. https://doi.org/10.1080/08923648909526659

Nafalski, A., Member, S., Nedic, Z., Machotka, J., Göl, Ö., Crichton, J., ... Murray, S. (2009). International collaboration in remote engineering laboratories : An approach to 
development. IEEE Transactions on Learning Technologies, 1-8.

$\mathrm{Ng}$, K. C. (2007). Replacing face-to-face tutorials by synchronous online technologies: Challenges and pedagogical implications. International Review of Research in Open and Distance Learning, 8(1), 1-15.

Nikolic, S., Ritz, C., Vial, P. J., Ros, M., \& Stirling, D. (2015). Decoding Student Satisfaction: How to Manage and Improve the Laboratory Experience. IEEE Transactions on Education, 58(3), 151-158. https://doi.org/10.1109/TE.2014.2346474

Ogot, M., Elliott, G., \& Glumac, N. (2003). An Assessment of In-Person and Remotely Operated Laboratories. Journal of Engineering Education, 92(January), 57-64. https://doi.org/10.1002/j.2168-9830.2003.tb00738.x

Park, J. J., Choe, N. H., Schallert, D. L., \& Forbis, A. K. (2017). The chemical engineering research laboratory as context for graduate students' training: The role of lab structure and cultural climate in collaborative work. Learning, Culture and Social Interaction, 13(March), 113-122. https://doi.org/10.1016/j.lcsi.2017.04.001

Patterson, D. A. (2011). Impact of a multimedia laboratory manual: Investigating the influence of student learning styles on laboratory preparation and performance over one semester. Education for Chemical Engineers, 6(1), e10-e30. https://doi.org/10.1016/j.ece.2010.10.001

Reid, N., \& Shah, I. (2007). The role of laboratory work in university chemistry. Chemistry Education Research and Practice, 8(2), 172-185. https://doi.org/10.1039/B5RP90026C

Selvaduray, G. S. (1995). Undergraduate engineering ceramics laboratory development undergraduate engineering ceramics laboratory development. International Journal of Engineering Education, 11(4 and 5), 374-379.

Sher, A. (2009). Assessing the relationship of student-instructor and student-student interaction to student learning and satisfaction in Web-based Online Learning Environment. Journal of Interactive Online Learning, 8(2), 102-120. Retrieved from http://www.ncolr.org/jiol/issues/pdf/8.2.1.pdf

Sonnenwald, D. H., Whitton, M. C., \& Maglaughlin, kelly L. (2003). Evaluating a scientific collaboratory: Results of a controlled experiment. ACM Transactions on ComputerHuman Interaction, 10(2), 150-176.

Stang, J. B., \& Roll, I. (2014). Interactions between teaching assistants and students boost engagement in physics labs. Physical Review Special Topics - Physics Education Research, 10(2), 1-15. https://doi.org/10.1103/PhysRevSTPER.10.020117

Tabachnick, B. G., \& Fidell, L. S. (2013). Using multivariate statistics (6th ed.). Boston: Pearson Education.

Teng, M., Considine, H., Nedic, Z., \& Nafalski, A. (2016). Current and future developments in the remote laboratory netlab. International Journal of Online Engineering (iJOE), 12(8), 4-12. https://doi.org/http://dx.doi.org/10.3991/ijoe.v12i08.6034

Tolba, A., \& Elawady, Y. H. (2016). Analysis , Design and implementation of a general framework for remote lab, (January 2011). https://doi.org/10.5120/1812-2344

Vuthaluru, R., Lindsay, E., Maynard, N., Ingram, G., Tade, M., Ang, M., \& Vuthaluru, H. (2013). Use of digital technologies in bridging the gap between face-to-face and remote engineering programs. 10th International Conference on Remote Engineering and 
Virtual Instrumentation, REV 2013, February 6, 2013 - February 8, 2013. https://doi.org/10.1109/REV.2013.6502888

Watai, L. L., Brodersen, A. J., \& Brophy, S. P. (2005). Designing effective electrical engineering laboratories using challenge-based instruction that reflect engineering process. In 2005 ASEE Annual conference and Exposition (pp. 1-22).

Webb, H. W., \& Webb, L. A. (2005). Dimensions of learning interaction in the IT-supported classroom. In Southern Association of Information Systems (pp. 41-47). Association for Information Systems. Retrieved from http://aisel.aisnet.org/sais2005/8

Zubía, J. G., \& Alves, G. R. (2011). Using remote labs in education, two little ducks in remote experimentation. (A. Del \& M. Bueno, Eds.) (8th ed.). Bilbao: University of Deusto. 
Please choose ONLY 5 of them that you think are most important and rank the ones you choose from 1-5 (where \#1 is the most important).

\begin{tabular}{|c|c|c|}
\hline \multicolumn{2}{|l|}{ Example interaction } & Rank \\
\hline \multirow{3}{*}{ Talking to other student you learn } & ..... about the procedures/lab equipment & \\
\hline & ..... how to analyse and interpret your results & \\
\hline & ..... about the basic theory behind the lab & \\
\hline \multirow{3}{*}{ Talking to a lab instructor you learn } & ..... about the procedures/lab equipment & \\
\hline & ..... how to analyse and interpret your results & \\
\hline & ..... about the basic theory behind the lab & \\
\hline \multirow{3}{*}{ Operating the equipment you learn } & ..... how to perform the experiment & \\
\hline & ..... to find possible errors in the experimental results & \\
\hline & $\begin{array}{l}\text {.... about theoretical concepts that govern the } \\
\text { experimental phenomena }\end{array}$ & \\
\hline \multirow{3}{*}{ Reading the laboratory Sheet/notes you learn } & ..... about the procedures/lab equipment & \\
\hline & ..... how to analyse and interpret your results & \\
\hline & ..... about the basic theory behind the lab & \\
\hline \multicolumn{2}{|c|}{ You learn about the basic theory behind the lab by using the internet on a smart device } & \\
\hline
\end{tabular}


Reflecting on the laboratory class you just completed:

1. (Student-Student Interactions) How significant was talking to another student about...

\begin{tabular}{|c|c|c|c|c|c|c|c|c|c|c|c|}
\hline the procedures, protocols or laboratory equipment? & & $\square$ & 吕 & 4 & 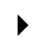 & $\Delta$ & $\nabla$ & 4 & 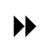 & W4 & مر \\
\hline the basic theoretical concepts behind the laboratory? & & $\square$ & 吕 & 4 & $\triangleright$ & $\Delta$ & $\nabla$ & 41 & $\boldsymbol{M}$ & W4 & مك \\
\hline analysing and interpreting your results? & & $\square$ & 吕 & 4 & 十 & $\Delta$ & $\nabla$ & 4 & 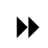 & K4 & ת \\
\hline engineering topics not directly related to the laboratory? & & $\square$ & 吕 & 4 & • & $\boldsymbol{\wedge}$ & $\nabla$ & 4 & 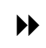 & K4 & S \\
\hline general topics not related to the laboratory? & & $\square$ & 吕 & 4 & • & $\Delta$ & $\nabla$ & 4 & $\omega$ & W4 & S \\
\hline What was your level of satisfaction with the above interactions? & & ص & 4 & D & $\Delta$ & $\nabla$ & 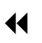 & $\|$ & W4 & حر & \\
\hline
\end{tabular}

2. (Student-Instructor Interactions) How significant was talking to the instructor about...

the procedures, protocols or laboratory equipment?

the basic theoretical concepts behind the laboratory?

analysing and interpreting your results?

engineering topics not directly related to the laboratory?

general topics not related to the laboratory?

What was your level of satisfaction with the above interactions?

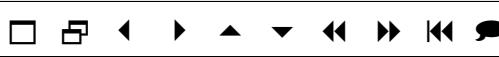

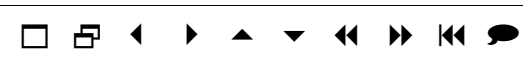

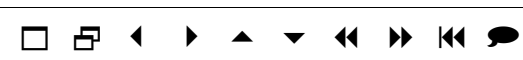

口古

$\square$ 古・ $・$ 十

吕4・、・4川

3. (Student-Equipment Interactions) At what level of significance, did you... use laboratory manual/instructions for conducting the experiment? use the Internet for laboratory related tasks

feel you were operating a real equipment for collecting the data

feel difficulty in operating equipment via internet

What was your level of satisfaction with the above interactions?

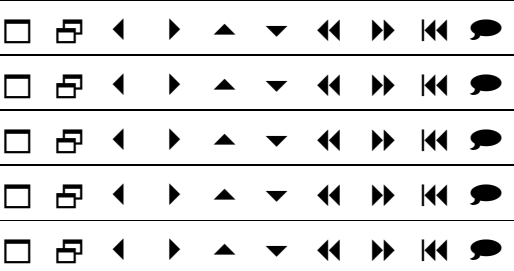

4. (Indirect Interactions) How significant was vour learning bv.....

observing other students' operation of the remote laboratory

listening to other students discussion

listening to other students asking an instructor for help/advice

What was your level of satisfaction with the above interactions?

- $\quad$ Significance: 1= Insignificant;

$10=$ Extremely significant

\begin{tabular}{|c|c|c|c|c|c|c|c|c|}
\hline$\square$ & 吕 & 4 & 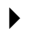 & $\Delta$ & $\nabla$ & $\$ 1$ & $\rightarrow \quad \mid k$ & $\Omega$ \\
\hline$\square$ & 吕 & 4 & $\triangleright$ & $\Delta$ & $\nabla$ & 4 & $\Rightarrow \quad 11$ & $\Omega$ \\
\hline$\square$ & 古 & 4 & $\triangleright$ & $\Delta$ & $\nabla$ & 11 & $\Rightarrow \quad \mid 11$ & $\Omega$ \\
\hline$\square$ & 占 & 4 & 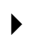 & $\Delta$ & $\nabla$ & 14 & $\Rightarrow \quad \mid 11$ & \\
\hline
\end{tabular}

\section{B.2. For face-to-face laboratory}

Questions for post-laboratory survey conducted in face-to-face laboratory under all interaction categories were the same except for the student-equipment interactions which are shown in the table below.

(Student-Equipment Interactions) At what level of significance, did you...

read the lab manual/instructions associated with this lab?

use the Internet for laboratory related tasks

operate the equipment for collecting the data

What was your level of satisfaction with the above interactions?

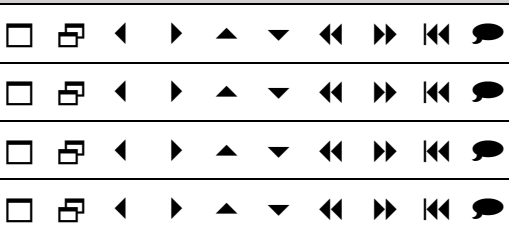




\begin{tabular}{|c|c|c|c|c|c|}
\hline $\begin{array}{l}\text { Please think about the laboratory 1a and 1b that you did today } \\
\text { in the Unit MCEN } 1000 \text { and answer as best you can the } \\
\text { following: }\end{array}$ & $\begin{array}{l}\text { Strongly } \\
\text { disagree }\end{array}$ & Disagree & $\begin{array}{l}\text { Neither } \\
\text { agree nor } \\
\text { disagree }\end{array}$ & Agree & $\begin{array}{l}\text { Strongly } \\
\text { agree }\end{array}$ \\
\hline $\begin{array}{l}\text { Reading the lab briefing sheet is an essential part of the lab } \\
\text { activity }\end{array}$ & $\square$ & ロ & 4 & • & $\Delta$ \\
\hline $\begin{array}{l}\text { I often referred to the lab briefing sheet for laboratory } \\
\text { procedures }\end{array}$ & $\square$ & 吕 & 4 & • & $\Delta$ \\
\hline $\begin{array}{l}\text { I often referred to the lab briefing sheet to learn concepts } \\
\text { behind the experiment }\end{array}$ & $\square$ & 口 & 1 & • & $\Delta$ \\
\hline $\begin{array}{l}\text { The lab briefing sheet contained all the important } \\
\text { information necessary for this lab }\end{array}$ & $\square$ & 口 & 4 & P & $\Delta$ \\
\hline $\begin{array}{l}\text { The present lab briefing sheet is sufficient for me to perform } \\
\text { the experiment by myself }\end{array}$ & $\square$ & 吕 & 4 & • & $\Delta$ \\
\hline $\begin{array}{l}\text { I was satisfied with the contents of the lab briefing sheet } \\
\text { provided to us }\end{array}$ & $\square$ & 口 & 4 & • & $\Delta$ \\
\hline
\end{tabular}

What improvements would you like to suggest in regards to:

\section{Theoretical concepts included in the briefing sheet}

\section{Instructions for laboratory procedures}

\section{Data collection and analysis of results}

Please provide any other suggestions for improving the lab briefing sheet for a better lab experience. 


\section{APPENDIX D: Laboratory-activity description and brief overview of the instruction sheets used in the study}

\section{D.1 Overview of the laboratory activity}

For both laboratory modes, the objective of the activity undertaken by students was to determine the relationship between the deflections of a simple beam of fixed dimensions and the downward force (load) applied to its mid-point and to confirm that the sum of the reactions at the support locations of the beam equalled the load applied. Students varied the applied load and measured the deflection of the beam at its mid-point while also recording the reaction forces at the support points. Further details of the experiment conducted in each mode are provided in [Blind].

\section{D.2 Conduct of the laboratory activity}

\section{D.2.1 Face-to-face laboratory mode}

Students worked together in groups of three or four students using the equipment that had already been set up. After giving a safety briefing, a graduate teaching assistant instructed students on experimental procedures by giving a demonstration of the equipment's operation and the data-acquisition process; thereafter the students conducted their investigation during which they physically interacted with the equipment, for example, to change the load. The instructor remained available throughout the one-hour session to assist and answer questions from students. At the end of the session, students submitted a (group) report comprising their data, calculations, and analysis of their results.

\section{D.2.2 Remotely operated laboratory mode}

Students worked together in pairs and accessed the equipment located at the University Technology Sydney (UTS) using a PC via the internet (from Perth or Melbourne). At the start of the session, the instructor explained how to open the link to the remote equipment and the features of the graphical user interface (GUI) followed by an overview of the actual experimental procedure. The instructor then remained in the room, available for consultation, throughout the one-hour session. After the completion of the experiment, student pairs (??? please confirm) were required to prepare laboratory report for submission one week later.

\section{D.3 Summary (in order of presentation) of contents of the laboratory-instruction sheets}

\section{D.3.1 Face-to-face laboratory mode}

1. Outline of the thoeretical concepts to be studied through the conduct of experiment

2. Basic definitions of the terms that form basis for the theoretical concepts

3. Schematic diagram to illustrate the experimental arrangement

4. Detailed step-by-step procedures to perform the experiment

5. Tables to assist students with collecting the required data from the experiment

6. Questions to guide students through the analysis of their the results after calculation

7. Marking rubric for the activity for both the instractor to grade the report and for students to understand the basis of the score they receive for their work

\section{D.3.2 Remotely operated laboratory}

1. Aim of the experiment and the theoretical concepts to be studied

2. Schematic diagram of the experimental arrangement and a photograph of the remote equipment

3. An illustration of the web interface (GUI) that the students use to manipulate the equipment

4. Detailed procedures on connecting with the remotely set-up equipment

5. The necessary operational steps to collect the data

6. Tables and equation for data collection and its analysis

7. Analysis questions for students to consider so as to arrive at overall findings for the experiment 